\title{
Traumatic surfing injuries in New Zealand: A descriptive epidemiology study
}

\author{
James Furness ${ }^{\text {Corresp., } 1}$, Katherine McArthur ${ }^{1}$, Debbie Remnant ${ }^{2}$, Darcy Jorgensen ${ }^{1}$, Catherine J Bacon ${ }^{2,3}$, Robert W \\ Moran $^{2}$, Wayne Hing ${ }^{1}$, Mike Climstein ${ }^{1,4,5}$ \\ ${ }^{1}$ Faculty of Health Sciences/ Water based Research Unit, Bond University, Gold Coast, QLD, Australia \\ 2 Osteopathy, Unitec Institute of Technology, Auckland, New Zealand \\ 3 Faculty of Medical and Health Sciences, University of Auckland, Auckland, New Zealand \\ 4 Physical Activity, Lifestyle, Ageing and Wellbeing Faculty Research Group/ Faculty of Health Sciences, University of Sydney, Sydney, NSW, Australia \\ 5 Faculty of Health, Southern Cross University, Gold Coast, QLD, Australia \\ Corresponding Author: James Furness \\ Email address: jfurness@bond.edu.au
}

Background. New Zealand (NZ) has nearly $14,000 \mathrm{~km}$ of coastline and a surfing population of approximately 315,000 surfers. Given its popularity, surfing has a high frequency of injury claims, however, there remains a lack of data on traumatic surfingrelated injuries from large population studies. The primary purpose of this study was to examine traumatic surfing injuries in NZ specific to injury incidence, duration, location, type, mechanism of injury and associated risk factors. Methods. A sample of selfidentified surfers currently living in NZ participated in an online retrospective crosssectional survey between December 2015 and July 2016. Demographic and surfing injury data were collected and analysed. Results. The survey yielded 1,473 respondents ( $18.3 \%$ female); a total of 502 surfers reported 702 major traumatic injuries with an overall incidence proportion of $0.34(95 \% \mathrm{Cl} 0.32-0.37)$. When comparing the number of injured surfers who sustained an injury at various body locations, a significantly higher proportion of competitive surfers, compared to recreational surfers, had an injury at the neck $(6.8 \%$ vs $\left.4 \%, \chi^{2}(1,1473)=5.84, P=0.019\right)$; $\operatorname{shoulder}\left(7.4 \%\right.$ vs $4.3 \%, \chi^{2}(1,1473)=6.34, P=$ $0.017)$, upper back ( $1 \%$ vs $\left.2.4 \%, \chi^{2}(1,1473)=4.77, P=0.043\right)$, lower back $(7 \%$ vs $3.1 \%$, $\left.\chi^{2}(1,1473)=11.98, P=0.001\right)$ and knee $\left(7 \%\right.$ vs $\left.3.4 \%, \chi^{2}(1,1473)=9.67, P=0.003\right) . A$ significantly higher proportion of surfers who performed aerial manoeuvres compared to those who did not reported a higher proportion of knee injuries $\left(9.7 \%\right.$ vs $3.9 \%, \chi^{2}(1,1473)$ $=13.00, P=0.001$ ). With respect to injury duration, the shoulder represented the largest proportion of chronic injuries (>3 months) $(44.4 \%)$, and the head and face represented the largest proportion of acute injuries ( $\leq 3$ months) ( $88 \%$ ). Muscle and tendon injuries were reported most frequently $(25,6 \%)$ and direct contact injuries accounted for $58.1 \%$ of all 
injury mechanisms. Key risk factors for traumatic injury included: competitive compared to recreational status ( $41.0 \%$ vs $30.1 \%$, Relative Risk $(R R)=1.36, P<0.001)$, ability to perform aerial manoeuvres ( $48.1 \%$ vs $31.8 \%, R R=1.51, P<0.001)$ and intermediate or above skill level surfers compared to beginner surfers $(35.8 \%$ vs $22.7 \%, \mathrm{RR}=1.58, P<$ 0.001 ). Conclusion. One third of recreational surfers sustained a major traumatic injury in the previous 12 months. For competitive or aerialist surfers the risk was greater, with this proportion approximately half. Overall, the head/face was the most common location of traumatic injury, with competitive surfers being more likely to sustain a neck, shoulder, lower back, and knee injury compared to recreational surfers. The shoulder was associated with the highest proportion of injuries of chronic duration. Future research should investigate injury mechanisms and causation using prospective injury monitoring to better underpin targeted injury prevention programs. 
1 Traumatic surfing injuries in New Zealand: A descriptive 2 epidemiology study

\author{
James Furness ${ }^{1 *}$, Katherine McArthur ${ }^{1}$, Debbie Remnant ${ }^{2}$, Darcy Jorgensen ${ }^{1}$, Catherine J \\ Bacon $^{2,3}$, Robert W Moran ${ }^{2}$, Wayne Hing ${ }^{1}$, Mike Climstein ${ }^{1,4,5}$ \\ ${ }^{1}$ Water Based Research Unit, Faculty of Health Sciences and Medicine, Bond University, \\ Robina, QLD, Australia \\ ${ }^{2}$ Osteopathy, Unitec Institute of Technology, Auckland, New Zealand \\ ${ }^{3}$ Faculty of Medical and Health Sciences, University of Auckland, Auckland, New Zealand \\ ${ }^{4}$ Faculty of Health, Southern Cross University, Gold Coast, QLD, Australia \\ ${ }^{5}$ Physical Activity, Lifestyle, Ageing and Wellbeing Faculty Research Group Faculty of Health \\ Sciences, University of Sydney, Lidcombe, NSW, Australia \\ Corresponding Author \\ James Furness ${ }^{1}$ \\ 2 Promethean way, Gold Coast, Robina, 4226, Australia \\ Email: jfurness@bond.edu.au
}

\begin{abstract}
:
Background. New Zealand (NZ) has nearly $14,000 \mathrm{~km}$ of coastline and a surfing population of approximately 315,000 surfers. Given its popularity, surfing has a high frequency of injury claims, however, there remains a lack of data on traumatic surfing-related injuries from large population studies. The primary purpose of this study was to examine traumatic surfing injuries in NZ specific to injury incidence, duration, location, type, mechanism of injury and associated risk factors.
\end{abstract}

Methods. A sample of self-identified surfers currently living in NZ participated in an online retrospective cross-sectional survey between December 2015 and July 2016. Demographic and surfing injury data were collected and analysed.

Results. The survey yielded 1,473 respondents ( $18.3 \%$ female); a total of 502 surfers reported 702 major traumatic injuries with an overall incidence proportion of 0.34 (95\% CI $0.32-0.37)$. When comparing the number of injured surfers who sustained an injury at various body locations, a significantly higher proportion of competitive surfers, compared to recreational surfers, had an injury at the neck $\left(6.8 \%\right.$ vs $\left.4 \%, \chi^{2}(1,1473)=5.84, P=0.019\right)$; shoulder $(7.4 \%$ vs $\left.4.3 \%, \chi^{2}(1,1473)=6.34, P=0.017\right)$, upper back $\left(1 \%\right.$ vs $\left.2.4 \%, \chi^{2}(1,1473)=4.77, P=0.043\right)$, lower back $\left(7 \%\right.$ vs $\left.3.1 \%, \chi^{2}(1,1473)=11.98, P=0.001\right)$ and knee $\left(7 \%\right.$ vs $3.4 \%, \chi^{2}(1,1473)=$ $9.67, P=0.003)$. A significantly higher proportion of surfers who performed aerial manoeuvres compared to those who did not reported a higher proportion of knee injuries $\left(9.7 \%\right.$ vs $3.9 \%, \chi^{2}$ $(1,1473)=13.00, P=0.001)$. With respect to injury duration, the shoulder represented the largest proportion of chronic injuries ( $>3$ months) $(44.4 \%)$, and the head and face represented the largest proportion of acute injuries ( $\leq 3$ months) $(88 \%)$. Muscle and tendon injuries were reported most frequently $(25.6 \%)$ and direct contact injuries accounted for $58.1 \%$ of all injury mechanisms. 
46 Key risk factors for traumatic injury included: competitive compared to recreational status

$47(41.0 \%$ vs $30.1 \%$, Relative Risk $(\mathrm{RR})=1.36, P<0.001)$, ability to perform aerial manoeuvres

$48 \quad(48.1 \%$ vs $31.8 \%, \mathrm{RR}=1.51, P<0.001)$ and intermediate or above skill level surfers compared

49 to beginner surfers $(35.8 \%$ vs $22.7 \%, \mathrm{RR}=1.58, P<0.001)$.

50

Conclusion. One third of recreational surfers sustained a major traumatic injury in the previous 12 months. For competitive or aerialist surfers the risk was greater, with this proportion approximately half. Overall, the head/face was the most common location of traumatic injury, with competitive surfers being more likely to sustain a neck, shoulder, lower back, and knee injury compared to recreational surfers. The shoulder was associated with the highest proportion of injuries of chronic duration. Performance of aerial manoeuvres was associated with increased number of knee injuries. Future research should investigate injury mechanisms and causation using prospective injury monitoring to better underpin targeted injury prevention programs.

\section{Introduction}

Surfing is a very popular aquatic sport and activity with an estimated 37 million surfers worldwide (Remnant et al. 2020) and with surfing's recent qualification into the Tokyo Olympics (International Surfing Association 2018) its popularity continues to grow (McArthur et al. 2020). The growth in popularity of surfing has also seen a growth in scientific research. A recently published systematic review by McArthur et al. (2020) revealed a total of 19 descriptive epidemiology studies specific to acute surfing injury. The location of these studies were in a range of countries including Brazil, United Kingdom, United States of America, Japan, Portugal and Norway, with a number of the included studies based out of Australia (Burgess et al. 2018; Dimmick et al. 2018; Furness et al. 2015; Lowdon et al. 1983; Lowdon et al. 1987; Taylor et al. 2004); however, no study was identified from New Zealand (NZ) despite the popularity of the sport.

The geography of NZ includes 14,000 kilometres of coastline, varied seafloors (sand, rock, gravel, and reef), swell provided from two oceans (the Tasman Sea and South Pacific Ocean), and varied beach exposure (spits, inlets, headlands and fiords) (Moran \& Webber 2013). Given this unique geography surfing is popular in NZ, with an estimated 315,000 surfers over the age of 15 within a population of 3.9 million adults (Remnant et al. 2020; Simas et al. 2019; Statistics New Zealand 2018). Surfing is not only a recreational pastime and competitive outlet for NZ residents but also popular with Māori, the indigenous people of NZ; with reports of surfing by Māori several hundred years ago prior to European settlement (Te Kanawa 2017). Given the broad participation base of surfing within NZ, a large cross-sectional study of surfing injuries is needed to provide unique and important information about the type of injuries that occur across the spectrum of recreational and competitive surfers. Understanding surfing aetiology in NZ, where the sport is already very popular, may reflect the range of injuries that will be sustained globally as surfing increases in popularity globally.

To the authors knowledge, only one study has investigated acute surfing injuries in NZ. Moran \& Webber (2013) investigated surfing related injuries requiring first aid on NZ beaches. This study however, included body surfing and body boarding and therefore limits its applicability to a surfing cohort. Furthermore, no musculoskeletal injuries such as joint sprains or muscular 
89

90

91

92

93

94

95

96

97

98

99

100

101

102

103

104

105

106

107

108

109

110

111

112

113

114

\section{Methods}

116

117

118

119

120

121

122

123

124

125

126

127

128

129

130

131

132

\section{Procedure}

\section{Participants}

strains were represented in the results, despite this injury type being widely represented in previous surf injury related research (Furness et al. 2015).

Other studies have explored beach and adventure sport related injuries occurring in NZ, however their primary aims were to analyse the number and cost of claims, prevalence of injury and risk of participation in various sports that result in injury (Bentley \& Page 2008; Bentley et al. 2007). While these studies fail to provide detailed information specific to injury type, mechanism and individual surfing related risk factors; they clearly show that surfing is one of the top three adventure sports with the highest injury claim counts within NZ (Bentley et al. 2007).

Previous research has investigated acute (Furness et al. 2015) or chronic (Furness et al. 2014; Nathanson et al. 2002) surfing related injuries and definitions of these terms have encompassed both the onset and duration of the injury. However, Verhagen \& Van Mechelen (2010) recommend that appropriate classification of terms for injury onset should be traumatic injury (caused by a single identifiable event) or gradual onset injury (caused by repeated microtrauma without a single identifiable event). Injuries can be further categorised into acute or chronic according to duration, whereby an acute injury is typically defined as one that is resolves within a 3-month period whilst a chronic injury lasts more than 3 months (Jordan et al. 2010). There is a paucity of epidemiological research specific to surfing using the injury definition of both injury onset (traumatic or gradual) and duration (acute or chronic), with only one study that has appropriately used these definitions, however this study focussed on gradual onset injuries only (Remnant et al. 2020).

Given the high prevalence of injury associated with surfing, the need for research into surfing related traumatic injuries that encompasses injuries of acute and chronic duration, and the lack of research in NZ despite its popularity there, the primary purpose of this study was to examine traumatic surfing injuries in NZ specific to injury incidence, duration, location, type, mechanism of injury and associated risk factors.

Ethical approval was granted by the Unitec Research Ethics Committee (2015-1032). A retrospective cross-sectional questionnaire was used to collect epidemiological data on surfing injuries from surfers via an online platform (Survey Monkey, Palo Alto, CA, USA). The questionnaire was piloted by twenty participants before being actively promoted from December $29^{\text {th }}, 2015$ to July $2^{\text {nd }}, 2016$. A dual recruitment process was used to promote the survey; the majority of participants ( $>95 \%$ ) accessing the questionnaire online and a small minority of participants completed the questionnaire through face-to-face interactions with a researcher at popular surf locations in NZ. News articles, advertisements on a popular surf report site, promotion through surfing related Facebook groups and community noticeboard pages, and paid Facebook advertisements on a specifically created Facebook community page for this study were used as media promotion of the questionnaire.

Participants who self-identified as "surfers currently in New Zealand" including both residents and those surfers visiting NZ and were aged 8 years or older were invited to complete the questionnaire. Parental or caregiver consent and supervision was required for participants 
133 aged under 16 years. Written consent was required for all participants. Surfing stance (either 134 natural or goofy) and type of surfboard predominantly used (either short-board, mini-mal, long135 board, or equal combination of more than one type of board) were used to further establish

136

137

138

139

140

141

142

143

144

145

146

147

148

149

150

151

152

153

154

155

156

157

158

159

160

161

162

163

164

165

166

167

168

169

170

171

172

173

174

175

176

177

178 participants as surfers. Only participants who had been an active surfer for at least 12 months were included in the data analysis, similar to previous research (Furness et al. 2015).

Assuming an estimated proportion of injuries of $50 \%$ and a confidence level of $95 \%$, a minimum of 1,068 respondents was calculated to be required to achieve a margin of error of three percentage points based on the 2014 estimated population of 155,000 surfers in NZ (Haughey et al. 2015; Remnant et al. 2020). This population estimate was also used by Remnant et al. (2020) who investigated gradual onset injuries from the same study.

\section{Questionnaire design}

The questionnaire was modified from a previous survey of Australian surfers (Furness et al. 2014; Furness et al. 2015) and structured in two sections. Section one included demographic questions determining current residence in NZ (a minimum of a 6-month stay), gender, age, ethnicity (allowing selection of more than one), years of surfing, participation type (recreational or competitive), time spent surfing (divided into summer and winter seasons), and surfing locations specific to NZ. An adapted version of the Hutt scale of surfing levels, which includes estimations of peel angle and wave height that can be successfully surfed, was also used to improve clarity regarding surfing ability (Hutt et al. 2001). Surfing ability was further categorised during data analysis as either 'beginner' (including 'absolute beginner' and 'beginner'), or 'experienced' (including 'intermediate', 'advanced' and 'expert'). During data analysis board use was also further categorised as either 'predominantly short board' (including 'short board' and 'equally short board \& mini-mal') or 'predominantly long board' (including 'mini-mal', 'long board (9ft plus)' and 'equally mini-mal \& long board'). There was an additional category that participants could select titled 'equally long and short board' which was not included in the above categories and filtered from the analysis. Competitive status was categorised as either; 'recreational' (including surfers who never competed in an event), or 'competitive' (including surfers who previously or currently competed in either a local, national or international event). Wave size was categorised as either; 'head height or smaller', or 'overhead or greater in height'. Aerialist manoeuvre capability was categorised as either; 'aerialist' (which included surfers who were able to propel themselves and the board in the air and land back on the water standing on the board) or non-aerialist.

Section two included questions about surfing-related injuries experienced in the preceding 12 months. Questions were specific to onset of injury, location, type, mechanism, diagnosis from a health professional, duration of injury, and subsequent management and treatments. Respondents were required to identify injuries as being either 'traumatic' or 'gradual' using descriptions adapted from the definitions of Verhagen \& Van Mechelen (2010). Traumatic injuries were defined as having a specific event or sudden impact that occurred while surfing just prior to any symptoms (i.e. pain) (Verhagen \& Van Mechelen 2010). For the purpose of this study, only injuries identified as 'traumatic' were analysed, all data pertaining to gradual onset injuries were previously published by Remnant et al. (2020). Traumatic injuries were further categorised as either 'major' or 'minor' using a method previously employed by surf injury research (Furness et al. 2014; Furness et al. 2015). Major injuries were defined as those seeking treatment from a health professional, and/or at least one day off surfing and/or at least one day off work. 
179 Treatment from a health professional represented any form of service actively sought by

180 participant due to the severity of the injury, including medical services, physiotherapy,

181 osteopathy, chiropractic, naturopathy, specialist and/or practitioners of traditional Māori healing,

182 traditional Chinese medicine, and acupuncture. Minor injuries were defined as those that did not

183 require time off work or surfing or require treatment. Only injuries categorised as 'major' were

184 analysed and presented.

185 To appropriately classify location of injury each body region was further divided into 10 body

186 parts, using a condensed version of the Orchard Sports Injury Classification System (Fuller et al.

187 2006; Verhagen \& Van Mechelen 2010). The design of this study allowed participants to

188 document more than one injury at each body location. Injury duration was either acute, defined

189 as injury timeframe less than 3 months or chronic duration defined as injury recovery or ongoing

190 timeframe greater than 3 months. The mechanism of injury was the movement that occurred just

191 before or contributed to the injury. Mechanism of injury was categorised into three key areas

192 which included direct contact (for example with the surfer's own board), approaching or riding

193 the wave (for example during paddling) or other (for example through contact with marine life).

194 Injury type was categorised into five groups (skin, bone, joint and ligament, muscle and tendon,

195 and nerve). These categories for both injury mechanism and type were the same definitions used

196 by Furness et al. (2015). The questionnaire also allowed participants to document whether they

197 were given a diagnosis from a health professional for the shoulder and knee only.

198

$\underline{\text { Injury Definitions }}$

200

201

202

203

204

205

206

207

208

209

210

211

212

213

214

Incidence. Risk and rates of injury are two measures of injury incidence, and have been previously defined by Knowles et al. (2006), where incidence proportion (IP) is the probability of an athlete getting injured over a 12-month period. To calculate IP, the number of surfers injured was divided by the total number of surfers exposed to risk (total injured surfers/total surfers). Incidence rate (IR) was defined as the incidence of injury over 1000 hours of surfing (total number of injuries/1000 hours surfing).

\section{Data Analysis}

Frequencies and descriptive statistics were used to summarise variables specific to injury location, injury type, and mechanisms of injury, participant ethnicity, and geographical regions commonly surfed. Chi-square test and relative risk (RR) were used to determine differences for categorical data and injury counts. Alpha was set at $P<0.05$ a priori to determine significance. IR and IP were calculated for competitive status and aerialist manoeuvre capability. SPSS statistics package (IBM SPSS Statistics 27.0, IBM Corp., Armonk, NY) was used to analyse the data.

\section{Results}

216 Participation and Physiological Demographics

217 After removal of 300 questionnaires due to incomplete in key variables of injury and/or surfing experience, 1,542 respondents completed the full questionnaire. After excluding another 69 respondents who had $<12$ months surfing experience, 1,473 respondents were included in the

220 final data analysis. The minimum and maximum ages were 8 to 74 years respectively with an 221 interquartile range of 26 to 42 years. No differences were identified in the number of injuries 
222

223

224

225

226

227

228

229

230

231

232

233

234

235

236

237

238

239

240

241

242

243

244

245

246

247

248

249

250

251

252

253

254

255

256

257

258

259

260

between male and females $\left(34.0 \%\right.$ versus $34.6 \%, \chi^{2}(1473)=0.036, P=0.85$, respectively). Table 1 presents participants' physiological and surfing demographics.

\section{(Please insert Table 1 here)}

Participants of thirty-one ethnicities participated in this study, with the most selected ethnicity being NZ-European $(n=1259,85.5 \%)$ and/or NZ-Māori $(n=181,12.3 \%)$ as participants were allowed to select multiple ethnicities. Participants could also select the region they predominantly surfed within NZ. Figure 1 represents the dispersion of these regions with Auckland $(30.9 \%)$ and Waikato (14.7\%) having the highest frequencies.

\section{(Please insert Figure 1 here)}

Incidence Rate (IR) and Incidence Proportion (IP)

Of the 1,473 eligible respondents, $502(34.1 \%)$ reported sustaining a major traumatic injury. From these injured surfers, a total of 702 major traumatic injuries were reported as respondents were able to report up to two injuries per body part. The overall IP and IR were calculated to be $0.34(0.32-0.37)$ and $2.23(2.06-2.39)$ respectively; a breakdown of both IR and IP for the various cohorts is presented in Table 2.

\section{(Please insert Table 2 here)}

\section{Injury Location}

Location. The highest frequency of injuries reported was to the head and face for the entire cohort, recreational, competitive and aerialist surfers $(23.6 \%, 26.8 \%, 19.9 \%$ and $21.8 \%$, respectively). Other commonly reported regions were ankle and neck for recreational surfers (13.2\% and $10.8 \%$ respectively); neck and shoulder for competitive surfers (13\% and 12.7\%) and knee and shoulder for aerialists (15.2\% and $13.9 \%$ respectively). Table 3 provides the frequency counts for all body locations.

When comparing the IP for individual body locations, a higher proportion of competitive compared to recreational surfers sustained injuries at the neck $\left(6.8 \% \mathrm{vs} 4 \%, \chi^{2}(1,1473)=5.84, P\right.$ $=0.019)$; shoulder $\left(7.4 \%\right.$ vs $\left.4.3 \%, \chi^{2}(1,1473)=6.34, P=0.017\right)$, upper back $\left(1 \%\right.$ vs $2.4 \%, \chi^{2}$ $(1,1473)=4.77, P=0.043)$, lower back $\left(7 \%\right.$ vs $\left.3.1 \%, \chi^{2}(1,1473)=11.98, P=0.001\right)$ and knee $\left(7 \%\right.$ vs $\left.3.4 \%, \chi^{2}(1,1473)=9.67, P=0.003\right)$. Figure 2 presents proportional differences between recreational and competitive surfers.

The IP was significantly higher for surfers who had the capacity to perform aerial manoeuvres, with a significantly higher proportion of knee injuries compared to those surfers who are unable to perform aerial manoeuvres $\left(9.7 \%\right.$ vs $\left.3.9 \%, \chi^{2}(1,1473)=13.00, P=0.001\right)$. 
264

265

266

267

268

269

270

271

272

273

274

275

276

277

278

279

280

281

282

283

284

285

286

287

288

289

290

291

292

293

294

295

296

297

298

299

300

301

302

303

(Please insert Table 3 here)

(Please insert Figure 2 here)

Duration: Shoulder injuries made up the largest proportion of chronic duration traumatic injuries $(44.4 \%)$ whereas the head and face revealed the largest proportion of acute duration injuries (88\%), see Figure 3 for further details.

\section{(Please insert Figure 3 here)}

Type: Muscle and tendon injuries were reported most frequently $(25.6 \%)$, followed by joint and ligament (23.9\%) and skin (20.8\%). Bone (9.9\%) and nerve injuries $(7.8 \%)$ occurred less frequently. Nervous system injuries such as brain injury or concussion $(3.5 \%)$, eye $(3 \%)$ and ear injuries such as a burst or perforated eardrum (1.5\%) were the least common injury types and were only applicable to the head/face region. Further injury type and body location details are presented in Supplementary File 1.

Mechanism: Direct contact injuries accounted for $58.1 \%$ of all injury mechanisms: approaching or riding the wave accounted for $35.3 \%$, with the remaining $6.6 \%$ as other (e.g. sustained from marine life). When specifically analysing direct contact mechanisms, the surfer being struck by their own board accounted for $44.6 \%$ of these injuries, followed by striking the seafloor $(23.5 \%)$ and striking the surface of the sea $(21.1 \%)$. When specifically analysing mechanisms associated with approaching or riding the wave the most common points of injury were during the take-off $(16.1 \%)$, whilst duck diving $(11.3 \%)$ and during a floater manoeuvre $(10.5 \%)$. A detailed breakdown of all mechanisms of injury are presented in Table 4.

\section{(Please insert Table 4 here)}

Diagnosis. A total of 135 of $702(19.2 \%)$ major traumatic injuries were given a formal diagnosis. In the shoulder $(\mathrm{n}=77)$, rotator cuff muscle tears were the predominant diagnosis (41.6\%), followed by ligament sprains (22.1\%) and subluxation/dislocation (22.1\%). A total of 58 major knee injuries were diagnosed. Cartilage or meniscus injury encompassed $43.1 \%$ of knee injuries diagnosed, followed by ligament sprains, 41.4\%. Other diagnoses included dislocation $(6.9 \%)$ and other $(8.6 \%)$. Details of knee and shoulder injury diagnosis by health care professionals are presented in Table 5.

\section{(Please insert Table 5 here)}

Peer) reviewing PDF | (2021:07:63648:1:0:NEW 9 Sep 2021) 
304

305

306

307

308

309

310

311

312

313

314

315

316

317

318

319

320

321

322

323

\section{4}

325

326

327

328

329

330

331

332

333

334

335

336

337

338

339

340

341

342

343

344

345

346

\section{Risk Factors}

The relative risk ratios were identified for several variables within this study. Intermediate or above skill level surfers were more likely to sustain an injury compared to beginner surfers $(35.8 \%$ vs $22.7 \%, \mathrm{RR}=1.58, P<0.001)$. Competitive surfers $(41 \%$ vs $30.1 \%, \mathrm{RR}=1.36, P<$ 0.001 ) and surfers with the ability to complete aerials sustained significantly more injuries than surfers who were not ( $48.1 \%$ vs $31.8 \%$, RR $1.51, \mathrm{P}<0.001)$. When analysing the short board versus long board categories participants who indicated that they rode both a long and short board equally $(\mathrm{n}=132)$ were excluded in the analysis. Predominantly riding a short board $(\mathrm{n}=1003)$ verses predominantly riding a long board $(n=338)$ increased injury risk $(35.4 \%$ vs $29.6 \%$; $R R=1.196$, $\mathrm{P}=0.051$ ), however this was not statistically significant.

An additional sub-analysis was conducted to determine the risk of sustaining an injury if the surfer could perform an aerial with the data set filtered to those surfers who rode a short board. This was conducted based on the assumption that a surfer riding a long board or mini mal could not complete an aerial. All participants who reported riding a long board or a mini mal or a combination of these two were excluded in the analysis. Those surfers who reported riding a short board $(n=919)$, a combination of min mal and short board $(n=137)$ or a combination of a short board and long board $(n=132)$ were included in the total data set of 1,135 surfers. The relative risk ratio was then calculated with those surfers who had an ability to complete aerials sustaining significantly more injuries $(49.0 \%$ versus $32.6 \%$, RR $1.50, \mathrm{P}<0.001)$.

\section{Discussion}

The primary purpose of this study was to examine traumatic surfing injuries specific to injury incidence, duration, location, type, mechanism of injury and associated risk factors in NZ surfers. Given that the total participant numbers exceeded the required estimated sample size calculation, this study provides a sample representative of the NZ surfing population. With over 1400 participants, this study is likely to provide a sample representative of the broad recreational and competitive NZ surfing population. Given the lack of surfing injury epidemiology research in $\mathrm{NZ}$, the large participation rates in the country, and the high injury claim counts, this large crosssectional study provides much needed data. Consequently, these results may reflect the range of injuries that are likely to be sustained globally as surfing increases in popularity.

\section{Incidence Rate, Incidence Proportion and Relative Risks}

This study revealed that the ability to perform an aerial manoeuvre resulted in the highest IP (0.48), followed by competitive status (IP 0.48) and recreational (IP 0.30) populations. When examining incidence rate (IR) measured by the number of injuries per 1000 hours surfed, the results were reversed where greater rates were seen in recreational surfers (IR 2.33) compared with aerialists (1.98). This reversed trend is explained as aerialists and competitive surfers had higher participation rates (hours per year) compared to recreational surfers, which in turn reduced the calculated IR. In summary, nearly one in every two aerialist and competitive surfers sustained an injury in the last year as opposed to one in every three recreational surfers, despite both groups having a lower IR (injuries per 1000 hours) compared to the recreational surfers. Similar results were reported by Furness et al. (2015) with aerialists showing a greater IP $(0.48)$ than competitive $(0.42)$ and recreational (0.35) surfers, and recreational surfers showing a higher IR (2.18) than

Peer) reviewing PDF | (2021:07:63648:1:0:NEW 9 Sep 2021) 
347

348

349

350

351

352

353

354

355

356

357

358

359

360

361

362

363

364

365

366

367

368

369

370

371

372

373

374

375

376

377

378

379

380

381

382

383

384

385

386

387

388

389

competitive (1.51) and aerialist (1.35) surfers. Nathanson et al. (2007) conducted a prospective study analysing all acute surfing injuries across 10 amateur and 22 professional competitions globally, from 1999 to 2005 . The calculated IR was four times higher than the current study at 6.6 significant injuries per 1000 hours of competitive surfing. Similarly, Inada et al. (2018) reported an IR of 6.6 injuries per 1000 hours of competitive surfing across 50 contests during the Japan Pro Surfing Tour between 2009 and 2016. A possible factor as to why both studies (Inada et al. 2018; Nathanson et al. 2007) had higher IRs compared to the current study is that both studies collected data prospectively at the time of the injury. Data collected retrospectively runs the risk of memory decay and it is highly likely that injuries are missed and or estimated hours surfed are over or underestimated thus misrepresenting the true IR and IP (Jenkins et al. 2002). It also needs to be highlighted that both studies used a professional cohort competing at a high level and thus the physiological demands are likely to be higher than their recreational counterparts potentially predisposing them to greater injury risk.

The highest relative risk ratio was seen in surfers who had the ability to perform an aerial, compared to those who could not perform this manoeuvre. This could be attributed to the higher loads absorbed through the lower limbs and awkward knee and ankle joint positions when landing these manoeuvres (Lundgren et al. 2014; Lundgren et al. 2016) resulting in an increased likelihood of injury (Furness et al. 2015; Lundgren et al. 2014). In addition to the kinematic challenges of the aerial, the amount of vertical force estimated during aerial manoeuvres is almost six times a surfers body weight, thus providing substantial stress within the lower body (Lundgren et al. 2016). While this rationale for a higher injury count in this cohort appears sound, it is not supported by the mechanism of injury data within this current study, which revealed only $1.7 \%$ of all mechanisms being attributed to aerials. It could be postulated that aerial manoeuvres are complex and difficult to execute (Forsyth et al. 2021) which requires more experience and practice, and therefore exposing the surfer to greater risk through more hours and years of surfing compared to other surfers such as beginners who are not performing these manoeuvres. Another possible theory is that the surfers who can complete aerials engage in more risk-taking manoeuvres and consequently have higher injury counts.

Higher relative risk ratios in competitive surfing could be attributed to the greater physiological demands of competitive surfing compared with typical recreational surfing sessions (Farley et al. 2017). Furthermore, the scoring of professional competitive surfing is based on wave difficulty, variety and combinations of major manoeuvres, speed, power and flow on the wave (World Surf League 2021), therefore requiring competitive surfers to push themselves physically further in training than a recreational surfer may do, so increasing the likelihood of injury.

\section{Injury Location, duration, type and mechanism}

Injuries to the head and face had the highest injury count (23.6\%), with neck injuries second (11.8\%), compared to all other locations. The current study results are similar to a recent systematic review by McArthur et al. (2020) who reported face, head and neck injuries represented 33.8\% of total acute injuries. Nine of 19 included studies reported the head, face and neck to be the most common body regions affected. Head, neck, and eyes $(31.7 \%)$ were also identified as the most common locations of injury by Moran \& Webber (2013) in their examination of surfing injuries requiring first aid at NZ beaches. 
390

391

392

393

394

395

396

397

398

399

400

401

402

403

404

405

406

407

408

409

410

411

412

413

414

415

416

417

418

419

420

421

422

423

424

425

426

427

428

429

430

431

432

433

434

435

When analysing injury locations between competitive and recreational surfers, several joints had significantly higher proportions of injuries, specifically the shoulder, lower back, and knee (see figure 2). Higher proportions of injuries in these locations could be explained by demands placed on these surfers previously discussed above. When looking at aerialists, the knee had the second highest injury count $(15.2 \%)$. A possible theory that links aerial manoeuvres and knee injury; is that successful completion of a aerial manoeuvre commonly involves placing the knee in a valgus position when landing (Forsyth et al. 2018). The knee joint may compensate for range of motion restrictions at the ankle and hip and be predisposed to injury (Devita \& Skelly 1992).

In addition to determining injury location, this study also presented results on duration of injury. The head and face appear to have the highest proportion of acute durations (less than 3 months) as opposed to the lower back (38\%), lower leg and ankle (36.7\%) and shoulder (44.4\%) which revealed high frequencies of chronic durations (greater than 3 months). This high proportion of chronic shoulder injury durations is an important finding as it presents the potential difficulties of surfers recovering from an injury at this location shoulder. Remnant et al. (2020) who investigated gradual onset injuries in surfers also revealed high injury counts at the shoulder of a chronic duration. There are several potential reasons as to why the shoulder is commonly associated with chronic injury. Firstly, 50\% the time spent surfing involves paddling (Farley et al. 2017); to put this in perspective, a two-hour recreational surf session will involve approximately 60 minutes of paddling and covering a distance of $5 \mathrm{~km}$ (Farley et al. 2017). This external load placed on the shoulder joint may predispose the shoulder to injury (specifically the rotator cuff). Increased training and competition volume and arm fatigue has been shown to be a risk factor of chronic shoulder injury in overhead sports such as baseball (Norton et al. 2019) and swimming (Khodaee et al. 2016). It could be further postulated that many of the surfers with a shoulder injury continue to participate in surfing despite symptoms or return to surfing despite inadequate recovery. This has previously been the case in the sport of swimming (Beach et al. 1992). In addition, many surfers may have underlying modifiable risk factors (such as range of motion deficits) which predisposes them to shoulder injuries of a chronic duration. This hypothesis has further been confirmed by Clarsen et al. (2014) who investigated handball players and demonstrated that reduced glenohumeral rotation, external rotation weakness and scapular dyskinesis were risk factors to chronic shoulder injury. In addition, swimmers with either high (100 degrees or greater) or low (less than 93 degrees) external rotation range of motion have been shown to be at significantly higher risk of developing shoulder pain (Walker et al. 2012). Lastly, the complexity of the shoulder joint and rehabilitation must not be neglected when postulating potential reasons for higher proportions of chronic shoulder injury (Cools et al. 2020). Traditionally, rehabilitation programs are designed to improve flexibility, strength, endurance, functional stability and motor control (Cools et al. 2020). Trying to address all of these issues, in addition to challenges with patient compliance provide further rationale for the shoulder having the highest proportion of chronic injury durations. Data specific to injury duration is unique to this study as previous research has often failed to address the nature of injury (traumatic or gradual onset) and the duration (acute or chronic) separately. Specifically the recent systematic review by McArthur et al. (2020) included studies that investigated injuries occurring from a specific event that lasted less than 3 months. Since this study reported almost a third of traumatic injuries are of chronic duration having a recovery period of greater than 3 months, previous studies potentially underestimate the prevalence of traumatic injuries, thus highlighting the strength of the current study.

Peer) reviewing PDF | (2021:07:63648:1:0:NEW 9 Sep 2021) 


\section{Injury Type}

438 When addressing injury type, muscle and tendon injuries were the most common (25.6\%), followed by joint and ligament injuries (23.9\%). Similarly Furness et al. (2015) identified muscular $(31.3 \%)$ and joint injuries $(28.7 \%)$ to be the most common types of injuries in Australian surfers.

441

442

443

444

445

446

447

448

449

450

451

452

453

454

455

456

457

458

459

460

461

462

463

464

465

466

467

468

469

470

471

472

473

474

475

476

477 In contrast, previous research by Moran \& Webber (2013) found lacerations and abrasions to be the most common nature of injury (59.2\%), however, this study lacked a category for sprains and strains in injury reporting. In that study bruising represented the second most common nature of injury (15.2\%) and could have included sprains or strains but would be indistinguishable from simple contusions. McArthur et al. (2020) found skin injuries to be the most common type of injury overall $(46.0 \%)$, followed by soft tissue injuries (22.6\%). Differences in injury type frequencies between studies could be explained by the definition and categories used and the location of where the data was collected. For example, data collected out of emergency departments (McArthur et al. 2020) or specific to first aid (Moran \& Webber 2013) may tend to have a higher representation of skin injuries as opposed to survey based data collection methods similar to the current study (Furness et al. 2015). Furthermore, increased manoeuvrability of modern boards, combined with a higher risk-taking propensity of surfers such as completing aerials and manoeuvres in the critical and most powerful parts of the wave may have led to an increase in muscle and joint related injuries (Furness et al. 2015).

The current study also allowed for participants to document a diagnosed injury type by a health professional at the knee and shoulder. The high frequency of cartilage and menisci (43.1\%) and ligamentous (41.4\%) injuries of the knee within the current study is supported by Hohn et al. (2018) who reported the most common knee diagnoses in professional surfers were medial collateral ligament (MCL) sprains (49\%) and meniscus tears (37\%). Similarly, Inada et al. (2018) reported the majority $(43.5 \%)$ of knee injuries in competitive surfers during competition were the MCL. These results may be explained by the large compressive loading forces experienced at the knee with aggressive turning movements required in sections of the wave and during manoeuvres such as floaters and aerials. Previous research has also described that MCL injuries tend to occur in surfers' back knees, caused by high compressive valgus forces on landing aerial manoeuvres (Burgess et al. 2018; Hohn et al. 2018).

The most common diagnosis at the shoulder was rotator cuff pathology (41.6\%). These results are not surprising given the paddling requirements of surfing involving several shoulder movements all of which involve active contraction of the rotator cuff. While this causal effect seems probable, very few studies have specifically investigated shoulder pathology in surfing populations (Langenberg et al. 2021). The findings of the current study are supported by a case series of 25 surfers which revealed that $31 \%$ of the surfers had rotator cuff tendonitis (McBride \& Fisher 2012). Remnant et al. (2020) investigated gradual onset injuries and found the rotator cuff injury diagnosis was the highest of all shoulder diagnoses within surfers in NZ. Given the high frequency of rotator cuff pathology further research is needed in understanding the pathogenesis of these pathologies to enable appropriate intervention.

\section{Injury Mechanism}


502

503

504

505

506

507

508

509

510

511

512

513

514

515

516

517

518

519 Future Research

Direct contact injuries (58.1\%) were the most common category of injury mechanisms in this study. Surfers being struck by their own boards was the most common mechanism of injury, representing the majority $(44.6 \%)$ of direct contact injuries. A systematic review which investigated acute and traumatic injuries also reported that being struck by a surfers own board (38.6\%) was the most common mechanism of injury overall (McArthur et al. 2020). Of all 19 included studies, 14 reported being struck by own board to be the most common mechanism of injury and four studies provided no data on injury mechanism. Moran \& Webber (2013) who examined surfing injuries requiring first aid in NZ also reported being struck by the surfer's own board represented half $(50.5 \%)$ of all reported injury mechanisms. The sharp rails and points of the modern resin boards, aimed at maximising performance may have exacerbated the capacity to inflict soft tissue trauma when impacting the surfer (Dimmick et al. 2018). It could be postulated that as the surfing popularity increases, surf line-ups will inevitably become more crowded and the risk of trauma from another's surfboard may increase, from that seen in the current study where this represented only $6.3 \%(n=44)$ of all injury mechanisms.

\section{$\underline{\text { Study Limitations and strengths }}$}

There are limitations and strengths of this study that need to be explicitly outlined when generalising our findings beyond this study. Most notably is the design of the study being retrospective as opposed to using a prospective data collection method. The evident limitation with retrospective survey design is the inability to accurately recall the injury or the details specific to the injury (Jenkins et al. 2002). While a prospective design is optimal it is not necessarily feasible given the coastal location of surfers, the lack of one centralised data collection location and that many recreational surfers do not belong to a surf or board-riders club or other organisation where this type of data could be captured. To date, the only prospective studies have involved competitive surfers belonging to a professional body (Inada et al. 2018; Nathanson et al. 2007) where injury data is captured at the time of injury. A further limitation of the study was the inability to provide details regarding injury management. The current study allowed for the respondent to document the type of practitioner (physiotherapist etc.) that attended for treatment, however no detail of the actual treatment that was provided. This study also used a very broad definition of a competitive surfer, which included current and previous competitive involvement and all levels of competitive surfing (such as local board rider clubs to those competing at an international level). Given the range of competitive levels caution should be applied when generalising results to all competitive surfers outside of this study.

A major strength of this study was the appropriate classification of injury onset by using the definitions of traumatic and gradual onset injuries. This further enabled injury durations to be appropriately classified as acute and chronic. Several previous surf specific epidemiological studies have not clearly delineated between injury onset and injury duration, limiting the understanding of these injuries (Furness et al. 2015; Nathanson et al. 2002; Taylor et al. 2004).

Peer] reviewing PDF | (2021:07:63648:1:0:NEW 9 Sep 2021) 
This study provides a foundational understanding of injury epidemiology and answers the initial step in the injury prevention cycle described by van Mechelen et al. (1992) of identifying the problem (step 1, injury registration). Also, this study begins to investigate the next step proposed by van Mechelen et al. (1992) in the injury prevention cycle that aims to address the mechanism and causes of injury. Further research is needed to provide musculoskeletal profiles of various surfing cohorts to identify potential causes (e.g., asymmetry in ROM or strength) and risk factors for sustaining an injury. For example, what is the normal shoulder strength profile of a surfer and do limitations or asymmetries in various movements result in higher incidence of shoulder injury? Alternatively, does hip and ankle range of motion influence knee injury prevalence? Prospective research is needed where profiles and assessments are conducted prior to injury to adequately determine injury risk factors. With respect to the head and face injuries, further research is required to evaluate the effectiveness of headgear in reducing the number and/or severity of head and face injuries in surfing before more thorough arguments can be made for their integration into surfing culture for safety.

Understanding mechanisms and risk factors of injury allows for a targeted prevention approach which highlights the third step in the injury prevention cycle (van Mechelen et al. 1992). In the final step of the injury prevention cycle the ability of a surf-specific strength and conditioning program to reduce injury incidence could be assessed (van Mechelen et al. 1992). Prevention programs have been implemented in numerous sports and are often not supported by clear evidence that injury is reduced through completing such a program (Cools et al. 2020). Ensuring higher quality research is completed will enable evidence-based programs to be implemented and assessed.

With the evidence outlined in the current study, prevention programs should look at initially screening surfers at higher risk (such as competitive and those completing aerials); assessing key injury locations for each specific cohorts (such as the shoulder and knee for those surfers completing aerials) for strength, range of motion and proprioception deficits. This information can then be used to inform an individualized and appropriate strength and conditioning program.

\section{Conclusion}

This study provides valuable information specific to surfing participation and injury epidemiology within NZ. One in every three recreational surfers sustained a traumatic injury and approximately one in every two competitive or aerialist surfers sustained a traumatic injury in a previous 12-month period. The head and face were the most common location of injury overall, with the shoulder having the highest proportion of injuries of a chronic duration, highlighting the long-standing recovery process at this location. Competitive surfers were more likely to sustain a neck, shoulder, upper back, lower back, and knee injury when compared to their recreational counterparts. The knee was a highly injured location for surfers completing aerial manoeuvres. Key risk factors for sustaining an injury included being an experienced surfer, performing aerial manoeuvres or competing in surfing competitions. Future research needs to build upon this knowledge and investigate mechanisms and causes of injury using musculoskeletal assessment and prospective injury research methods, thus enabling targeted injury prevention programs. 


\section{References}

565 Beach ML, Whitney SL, and Dickoff-Hoffman SA. 1992. Relationship of Shoulder Flexibility, Strength, and Endurance to Shoulder Pain in Competitive Swimmers. Journal of Orthopaedic \& Sports Physical Therapy 16:262-268. 10.2519/jospt.1992.16.6.262

Bentley TA, and Page SJ. 2008. A decade of injury monitoring in the New Zealand adventure tourism sector: A summary risk analysis. Tourism Management 29:857-869. https://doi.org/10.1016/j.tourman.2007.10.003

Bentley TA, Page SJ, and Macky KA. 2007. Adventure tourism and adventure sports injury: The New Zealand experience. Applied Ergonomics 38:791-796. https://doi.org/10.1016/j.apergo.2006.10.007

Burgess A, Swain MS, and Lystad RP. 2018. An Australian survey on health and injuries in adult competitive surfing. The Journal of sports medicine and physical fitness 59. 10.23736/S0022-4707.18.08381-0

Clarsen B, Bahr R, Andersson SH, Munk R, and Myklebust G. 2014. Reduced glenohumeral rotation, external rotation weakness and scapular dyskinesis are risk factors for shoulder injuries among elite male handball players: a prospective cohort study. British Journal of Sports Medicine 48:1327.

Cools AM, Maenhout AG, Vanderstukken F, Declève P, Johansson FR, and Borms D. 2020. The challenge of the sporting shoulder: From injury prevention through sport-specific rehabilitation toward return to play. Annals of Physical and Rehabilitation Medicine:101384. https://doi.org/10.1016/j.rehab.2020.03.009

Devita P, and Skelly WA. 1992. Effect of landing stiffness on joint kinetics and energetics in the lower extremity. Med Sci Sports Exerc 24:108-115.

Dimmick S, Gillett M, Buchan C, Sheehan P, Franks M, Ratchford A, Porges K, Day R, Milne T, and Anderson S. 2018. Prospective analysis of surfing and bodyboard injuries. Trauma $0: 1460408617753660.10 .1177 / 1460408617753660$

Farley O, Abbiss CR, and Sheppard J. 2017. Performance analysis of surfing: a review. Journal of strength and conditioning research 31:260-271. 10.1519/JSC.0000000000001442

Forsyth JR, Richards CJ, Tsai M-C, Whitting JW, Riddiford-Harland DL, Sheppard JM, and Steele JR. 2021. Rate of loading, but not lower limb kinematics or muscle activity, is moderated by limb and aerial variation when surfers land aerials. Journal of Sports Sciences:1-9. 10.1080/02640414.2021.1898167

Forsyth JR, Riddiford-Harland DL, Whitting JW, Sheppard JM, and Steele JR. 2018. Understanding successful and unsuccessful landings of aerial maneuver variations in professional surfing. Scandinavian journal of medicine \& science in sports 28:16151624. https://doi.org/10.1111/sms.13055

Fuller CW, Ekstrand J, Junge A, Andersen TE, Bahr R, Dvorak J, Hägglund M, McCrory P, and Meeuwisse WH. 2006. Consensus statement on injury definitions and data collection procedures in studies of football (soccer) injuries. Scandinavian journal of medicine \& science in sports 16:83-92.

Furness J, Hing W, Abbott A, Walsh J, Sheppard JM, and Climstein M. 2014. Retrospective analysis of chronic injuries in recreational and competitive surfers: injury location, type, and mechanism. International Journal of Aquatic Research and Education 8:277-287. 10.1123/ijare.2013-0032 
608

609

610

611

612

613

614

615

616

617

618

619

620

621

622

623

624

625

626

627

628

629

630

631

632

633

634

635

636

637

638

639

640

641

642

643

644

645

646

647

648

649

650

651

652

Furness J, Hing W, Walsh J, Abbott A, Sheppard JM, and Climstein M. 2015. Acute injuries in recreational and competitive surfers: incidence, severity, location, type, and mechanism. The American Journal of Sports Medicine 43:1246-1254. 10.1177/0363546514567062

Haughey K, Gray A, and Heffield J. 2015. Sport and Active Recreation in the Lives of New Zealand Adults. 2013/14 Active New Zealand Survey Results (pdf). Wellington: Sport New Zealand.

Hohn E, Robinson S, Merriman J, Parrish R, and Kramer W. 2018. Orthopedic Injuries in Professional Surfers: A Retrospective Study at a Single Orthopedic Center. Clinical journal of sport medicine : official journal of the Canadian Academy of Sport Medicine. 10.1097/JSM.0000000000000596

Hutt JA, Black KP, and Mead ST. 2001. Classification of surf breaks in relation to surfing skill. Journal of Coastal Research:66-81.

Inada K, Matsumoto Y, Kihara T, Tsuji N, Netsu M, Kanari S, Yakame K, and Arima S. 2018. Acute injuries and chronic disorders in competitive surfing: From the survey of professional surfers in Japan. Sports Orthopaedics and Traumatology 34:256-260. https://doi.org/10.1016/j.orthtr.2018.03.107

International Surfing Association. 2018. International Olympic Committee and ISA Confirm Qualification Process for Surfing Competition at Tokyo 2020. Available at https://isasurf.org/tokyo-2020-qualification/.

Jenkins P, Earle-Richardson G, Slingerland DT, and May J. 2002. Time dependent memory decay. American Journal of Industrial Medicine 41:98-101. 10.1002/ajim.10035

Jordan JL, Holden MA, Mason EE, and Foster NE. 2010. Interventions to improve adherence to exercise for chronic musculoskeletal pain in adults. Cochrane Database of Systematic Reviews:1-23. 10.1002/14651858.CD005956.pub2

Khodaee M, Edelman GT, Spittler J, Wilber R, Krabak BJ, Solomon D, Riewald S, Kendig A, Borgelt LM, Riederer M, Puzovic V, and Rodeo S. 2016. Medical Care for Swimmers. Sports Medicine - Open 2:27. 10.1186/s40798-016-0051-2

Knowles SB, Marshall SW, and Guskiewicz KM. 2006. Issues in estimating risks and rates in sports injury research. Journal of Athletic Training. United States: National Athletic Trainers Association. p 207-215.

Langenberg LC, Vieira Lima G, Heitkamp SE, Kemps FLAM, Jones MS, Moreira MAdAG, and Eygendaal D. 2021. The Surfer's Shoulder: A Systematic Review of Current Literature and Potential Pathophysiological Explanations of Chronic Shoulder Complaints in Wave Surfers. Sports Medicine - Open 7:2. 10.1186/s40798-020-00289-0

Lowdon BJ, Pateman NA, and Pitman AJ. 1983. Surfboard-riding injuries. The Medical Journal of Australia 2:613-616.

Lowdon BJ, Pitman AJ, Pateman NA, and Kenneth R. 1987. Injuries to international competitive surfboard riders. The Journal of sports medicine and physical fitness 27:57-63.

Lundgren L, Nimphius S, Sheppard JM, Brown T, and Butel M. 2014. High ankle sprain : the new elite surfing injury? International SportMed Journal 15:321-327. doi:10.10520/EJC164106

Lundgren LE, Tran TT, Nimphius S, Raymond E, Secomb JL, Farley ORL, Newton RU, and Sheppard JM. 2016. Comparison of impact forces, accelerations and ankle range of motion in surfing-related landing tasks. Journal of Sports Sciences 34:1051-1057. $10.1080 / 02640414.2015 .1088164$

Peer) reviewing PDF | (2021:07:63648:1:0:NEW 9 Sep 2021) 
653

654

655

656

657

658

659

660

661

662

663

664

665

666

667

668

669

670

671

672

673

674

675

676

677

678

679

680

681

682

683

684

685

686

687

688

689

690

691

McArthur K, Jorgensen D, Climstein M, and Furness J. 2020. Epidemiology of Acute Injuries in Surfing: Type, Location, Mechanism, Severity, and Incidence: A Systematic Review. Sports 8:25. 10.3390/sports8020025

McBride A, and Fisher J. 2012. Shoulder injury in professional surfers. Journal of Science and Medicine in Sport 15:S139. https://doi.org/10.1016/i.jsams.2012.11.336

Moran K, and Webber J. 2013. Surfing injuries requiring first aid in New Zealand, 2007-2012. International Journal of Aquatic Research and Education p192-203.

Nathanson A, Bird S, Dao L, and Tam-Sing K. 2007. Competitive Surfing Injuries. The American Journal of Sports Medicine 35:113-117. 10.1177/0363546506293702

Nathanson A, Haynes P, and Galanis D. 2002. Surfing injuries. The American journal of emergency medicine 20:155-160. 10.1053/ajem.2002.32650

Norton R, Honstad C, Joshi R, Silvis M, Chinchilli V, and Dhawan A. 2019. Risk Factors for Elbow and Shoulder Injuries in Adolescent Baseball Players: A Systematic Review. Am J Sports Med 47:982-990. 10.1177/0363546518760573

Remnant D, Moran RW, Furness J, Climstein M, Hing WA, and Bacon CJ. 2020. Gradual-onset surfing-related injuries in New Zealand: A cross-sectional study. Journal of Science and Medicine in Sport 23:1049-1054. https://doi.org/10.1016/j.jsams.2020.05.010

Simas V, Remnant D, Furness J, Bacon CJ, Moran RW, Hing WA, and Climstein M. 2019. Lifetime prevalence of exostoses in New Zealand surfers. Journal of Primary Health Care 11:47-53. https://doi.org/10.1071/HC18097

Statistics New Zealand. 2018. National population estimates: At 30 June 2018. Available at https://www.stats.govt.nz/information-releases/national-population-estimates-at-30-june2018.

Taylor, Bennett D, Carter M, Garewal D, and Finch CF. 2004. Acute injury and chronic disability resulting from surfboard riding. Journal of Science and Medicine in Sport 7:429-437. 10.1016/s1440-2440(04)80260-3

Te Kanawa W. 2017. Native Affairs Summer Series - Ancient Māori surfing. Available at https://www.teaomaori.news/native-affairs-summer-series-ancient-maori-surfing.

van Mechelen W, Hlobil H, and Kemper HCG. 1992. Incidence, Severity, Aetiology and Prevention of Sports Injuries. Sports Medicine 14:82-99. 10.2165/00007256-19921402000002

Verhagen E, and Van Mechelen W. 2010. Sports injury research. Oxford: Oxford University Press.

Walker H, Gabbe B, Wajswelner H, Blanch P, and Bennell K. 2012. Shoulder pain in swimmers: A 12-month prospective cohort study of incidence and risk factors. Physical Therapy in Sport 13:243-249. https://doi.org/10.1016/j.ptsp.2012.01.001

World Surf League. 2021. Rules and Regulations. Available at https://www.worldsurfleague.com/pages/rules-and-regulations. 
Table $\mathbf{1}$ (on next page)

Participant physiological and surfing demographics 
1 Table 1: Participant physiological and surfing demographics

2

\begin{tabular}{lccc}
\hline & Total $(\mathrm{n}=1,473)$ & Males $(\mathrm{n}=1,204)$ & Females $(\mathrm{n}=269)$ \\
\hline Physiological demographics, mean \pm SD & & & \\
Age, y & $34.6 \pm 11.9$ & $35.3 \pm 12.3$ & $31.4 \pm 9.3$ \\
Weight, kg & $77.9 \pm 14.0$ & $81.3 \pm 12.5$ & $62.5 \pm 8.8$ \\
Height, m & $1.77 \pm 0.1$ & $1.80 \pm 0.1$ & $1.67 \pm 0.1$ \\
Body mass index, kg/m ${ }^{2}$ & $24.8 \pm 4.4$ & $25.3 \pm 4.3$ & $22.7 \pm 4.3$ \\
Surfing demographics & & & \\
Time surfing summer, h, mean \pm SD & $147.2 \pm 166.4$ & $152.14 \pm 167.0$ & $125.25 \pm 162.5$ \\
Time surfing winter, h, mean \pm SD & $66.9 \pm 109.7$ & $70.7 \pm 111.5$ & $50.1 \pm 99.9$ \\
Time surfing, h/y, mean \pm SD & $214.1 \pm 251.2$ & $222.8 \pm 251.2$ & $175.3 \pm 248.1$ \\
Competitive involvement, $\mathrm{n}(\%)$ & $542(36.8)$ & $466(38.7)$ & $76(28.3)$ \\
Aerialist, $\mathrm{n}(\%)$ & $206(14.0)$ & $202(16.8)$ & $4(1.5)$ \\
\hline
\end{tabular}

3 


\section{Table 2 (on next page)}

Major traumatic injury incidence proportion and incidence rate by competitive involvement, ability to perform aerials and overall.

${ }^{a}$ Values in parentheses are $95 \% \mathrm{Cls}$; ${ }^{b}$ as each surfer could report on more than one injury at the same site this value refers to the total number of injuries; ${ }^{c}$ Total refers to the sum of the number of recreational and competitive surfers combined as aerialist were both recreational and competitive surfers. 
1 Table 2: Major traumatic injury incidence proportion and incidence rate by competitive 2 involvement, ability to perform aerials and overall.

3

\begin{tabular}{ccccccc}
\hline & $\begin{array}{c}\text { Number } \\
\text { of } \\
\text { injured } \\
\text { surfers } \\
(\mathrm{n})\end{array}$ & $\begin{array}{c}\text { Total } \\
\text { surfers } \\
(\mathrm{n})\end{array}$ & $\begin{array}{c}\text { Incidence } \\
\text { Proportion: } \\
\text { Total injured } \\
\text { surfers/Total } \\
\text { surfers }^{\mathbf{a}}\end{array}$ & $\begin{array}{c}\text { Cumulative } \\
\text { number of }_{\text {injuries }}{ }^{\mathbf{2}}\end{array}$ & $\begin{array}{c}\text { Cumulative } \\
\text { Hours surfed } \\
\text { per year }\end{array}$ & $\begin{array}{c}\text { Incidence Rate: } \\
\text { Total number } \\
\text { of } \\
\text { Injuries/1000 } \\
\text { hours surfed }\end{array}$ \\
\hline Recreational & 280 & 931 & $\begin{array}{c}0.30 \\
(0.27-0.33)\end{array}$ & 380 & 163,222 & $2.33(2.09-2.56)$ \\
Competitive & 222 & 542 & $\begin{array}{c}0.41 \\
(0.37-0.45)\end{array}$ & 322 & 152,194 & $2.11(1.88-2.35)$ \\
\hline Total & $\mathbf{5 0 2}$ & $\mathbf{1 , 4 7 3}$ & $\begin{array}{c}\mathbf{0 . 3 4} \\
\mathbf{( 0 . 3 2 - 0 . 3 7 )}\end{array}$ & $\mathbf{7 0 2}$ & $\mathbf{3 1 5 , 4 1 6}$ & $\mathbf{2 . 2 3}(\mathbf{2 . 0 6 - 2 . 3 9 )}$ \\
\hline Aerialist & 99 & $\mathbf{2 0 6}$ & $\begin{array}{c}0.48 \\
(0.41-0.54)\end{array}$ & 151 & 76,138 & $1.98(1.67-2.30)$ \\
\hline
\end{tabular}

${ }^{a}$ Values in parentheses are $95 \%$ CIs; ${ }^{b}$ as each surfer could report on more than one injury at the same site this value refers to the total number of injuries; " Total refers to the sum of the number of recreational and competitive surfers combined as aerialist were both recreational and competitive surfers. 


\section{Table 3(on next page)}

Location and total number of major traumatic injuries for surfers in New Zealand

${ }^{a}$ Total refers to the sum of the number of recreational and competitive surfers combined as aerialist were both recreational and competitive surfers. 
1 Table 3: Location and total number of major traumatic injuries for surfers in New Zealand

2

\begin{tabular}{lccccc}
\hline \multirow{2}{*}{ Site } & \multicolumn{2}{c}{ Total Injuries $^{\mathbf{a}}$} & Recreational & Competitive & Aerialist Injuries \\
\cline { 2 - 5 } & $\mathrm{n}$ & $\%$ & $\mathrm{n}(\%)$ & $\mathrm{n}(\%)$ & $\mathrm{n}(\%)$ \\
\hline Head Face & 166 & 23.6 & $102(26.8)$ & $64(19.9)$ & $33(21.8)$ \\
Neck & 83 & 11.8 & $41(10.8)$ & $42(13.0)$ & $12(7.9)$ \\
Shoulder & 81 & 11.5 & $40(10.5)$ & $41(12.7)$ & $21(13.9)$ \\
Arm & 36 & 5.1 & $23(6.1)$ & $13(4.0)$ & $10(6.6)$ \\
Rib sternum & 41 & 5.8 & $24(6.3)$ & $17(5.3)$ & $7(4.6)$ \\
Upper back & 22 & 3.1 & $9(2.4)$ & $13(4.0)$ & $5(3.3)$ \\
Low Back & 71 & 10.1 & $31(8.2)$ & $40(12.4)$ & $15(9.9)$ \\
Hip / Groin & 47 & 6.7 & $24(6.3)$ & $23(7.1)$ & $12(7.9)$ \\
Knee & 76 & 10.8 & $36(9.5)$ & $40(12.4)$ & $23(15.2)$ \\
Lower Leg /Ankle & 79 & 11.3 & $50(13.2)$ & $29(9.0)$ & $13(8.6)$ \\
\hline Total & 702 & 100 & $380(100)$ & $322(100)$ & $151(100)$ \\
aTotal refers to the sum of the number of recreational and competitive surfers combined as aerialist were both recreational and competitive \\
surfers.
\end{tabular}


Table 4 (on next page)

Mechanism and site of major traumatic injuries 
Table 4: Mechanism and site of major traumatic injuries

2

\begin{tabular}{|c|c|c|c|c|c|c|c|c|c|c|c|}
\hline \multirow[b]{2}{*}{$\begin{array}{l}\text { Mechanism of } \\
\text { Injury }\end{array}$} & \multirow[b]{2}{*}{$\begin{array}{c}\text { Head/ } \\
\text { Face }\end{array}$} & \multirow[b]{2}{*}{ Neck } & \multirow[b]{2}{*}{ Shoulder } & \multicolumn{4}{|c|}{ Site of Injury } & \multirow[b]{2}{*}{$\begin{array}{l}\text { Hip/ } \\
\text { Groin }\end{array}$} & \multirow[b]{2}{*}{ Knee } & \multirow[b]{2}{*}{$\begin{array}{c}\text { Ankle/ } \\
\text { Lower leg }\end{array}$} & \multirow[b]{2}{*}{$\begin{array}{l}\text { Total, } \\
\text { n (\%) }\end{array}$} \\
\hline & & & & $\begin{array}{c}\text { Upper } \\
\text { back }\end{array}$ & $\begin{array}{c}\text { Rib/ } \\
\text { Sternum }\end{array}$ & Arm & Low back & & & & \\
\hline \multicolumn{12}{|l|}{ Direct contact injuries } \\
\hline Struck (own board) & 93 & 11 & 7 & 2 & 18 & 13 & 3 & 5 & 6 & 24 & $182(25.9)$ \\
\hline $\begin{array}{l}\text { Struck (other } \\
\text { board) }\end{array}$ & 16 & 2 & 3 & 1 & 1 & 1 & 7 & 3 & 2 & 8 & $44(6.3)$ \\
\hline Striking seafloor & 18 & 23 & 11 & 4 & 3 & 8 & 6 & - & 5 & 18 & $96(13.7)$ \\
\hline Total, $n$ & 144 & 63 & 40 & 13 & 28 & 22 & 21 & 11 & 14 & 52 & $408(58.1)$ \\
\hline \multicolumn{12}{|l|}{ Approach/wave riding } \\
\hline Paddling & 1 & 1 & 8 & 1 & - & 1 & 3 & 1 & - & - & $16(2.3)$ \\
\hline Duck diving & 3 & 4 & 14 & 2 & 1 & 1 & 2 & - & 1 & - & $28(4)$ \\
\hline Take off & 3 & 4 & 2 & 2 & 1 & 1 & 9 & 6 & 7 & 5 & $40(5.7)$ \\
\hline Bottom turn & - & - & - & - & - & - & 4 & 4 & 4 & 1 & $13(1.9)$ \\
\hline Top turn & - & 1 & 2 & 1 & - & - & 4 & 5 & 9 & 3 & $25(3.6)$ \\
\hline Cut back & - & - & - & - & - & - & 5 & 3 & 9 & 1 & $18(2.6)$ \\
\hline Floater & 3 & 2 & 3 & 1 & 1 & - & 3 & 2 & 7 & 4 & $26(3.7)$ \\
\hline Aerial & 1 & - & 1 & 1 & - & 1 & 1 & 1 & 4 & 2 & $12(1.7)$ \\
\hline Riding wave face & 1 & 2 & 1 & - & 1 & 1 & - & 2 & 4 & 1 & $13(1.9)$ \\
\hline Tube riding & 5 & 3 & 3 & - & 2 & - & 4 & 2 & 3 & 1 & $23(3.3)$ \\
\hline Wave force & 1 & 2 & 3 & - & - & - & 2 & 1 & 1 & - & $10(1.4)$ \\
\hline Total, $n$ & 19 & 19 & 38 & 8 & 9 & 5 & 43 & 31 & 54 & 22 & $248(35.3)$ \\
\hline \multicolumn{12}{|l|}{ Other } \\
\hline $\begin{array}{l}\text { Marine life } \\
\text { encounter }\end{array}$ & 3 & - & - & - & - & 2 & - & - & - & 1 & $6(0.9)$ \\
\hline Other* & - & 1 & 3 & 1 & 4 & 7 & 7 & 5 & 8 & 4 & $40(5.7)$ \\
\hline Total, $n$ & 3 & 1 & 3 & 1 & 4 & 9 & 7 & 5 & 8 & 5 & $46(6.6)$ \\
\hline Total, n & 166 & 83 & 81 & 22 & 41 & 36 & 71 & 47 & 76 & 79 & $702(100)$ \\
\hline
\end{tabular}

$3 *$ Where possible the text provided was re-coded into the pre-specified mechanisms (such as Paddling etc.), however in the cases where this was not possibe due

4 to the vast differences in the responses the mechanism remained as 'Other'. 


\section{Table 5 (on next page)}

Injury diagnosis provided by health professional for the shoulder and knee 
1 Table 5: Injury diagnosis provided by health professional for the shoulder and knee

2

\begin{tabular}{llccc}
\hline Location & Diagnosis & Injury 1, $\mathrm{n}$ & Injury $2, \mathrm{n}$ & Total, $\mathrm{n}(\%)$ \\
\hline \multirow{5}{*}{ Shoulder } & Ligament sprain & 16 & 1 & $17(22.1)$ \\
& Dislocation/Subluxation & 16 & 1 & $17(22.1)$ \\
& Cartilage & 3 & 0 & $3(3.9)$ \\
& Rotator cuff & 32 & 0 & $32(41.6)$ \\
& AC joint & 6 & 0 & $6(7.8)$ \\
& Unknown/Other & 2 & 0 & $2(2.6)$ \\
& Total & 75 & 2 & $77(100)$ \\
\hline \multirow{5}{*}{ Knee } & Ligament sprain & 23 & 1 & $24(41.4)$ \\
& Cartilage/Meniscus & 22 & 3 & $25(43.1)$ \\
& Dislocation & 3 & 1 & $4(6.9)$ \\
& Unknown/Other & 5 & 0 & $5(8.6)$ \\
& Total & 53 & 5 & $58(100)$ \\
\hline
\end{tabular}

3

4 
Figure 1

Distribution of primary regions surfed within New Zealand

Note: A category of 'Other' was used which represented $1.4 \%$ of responses as the exact location could not be determined or was outside of NZ

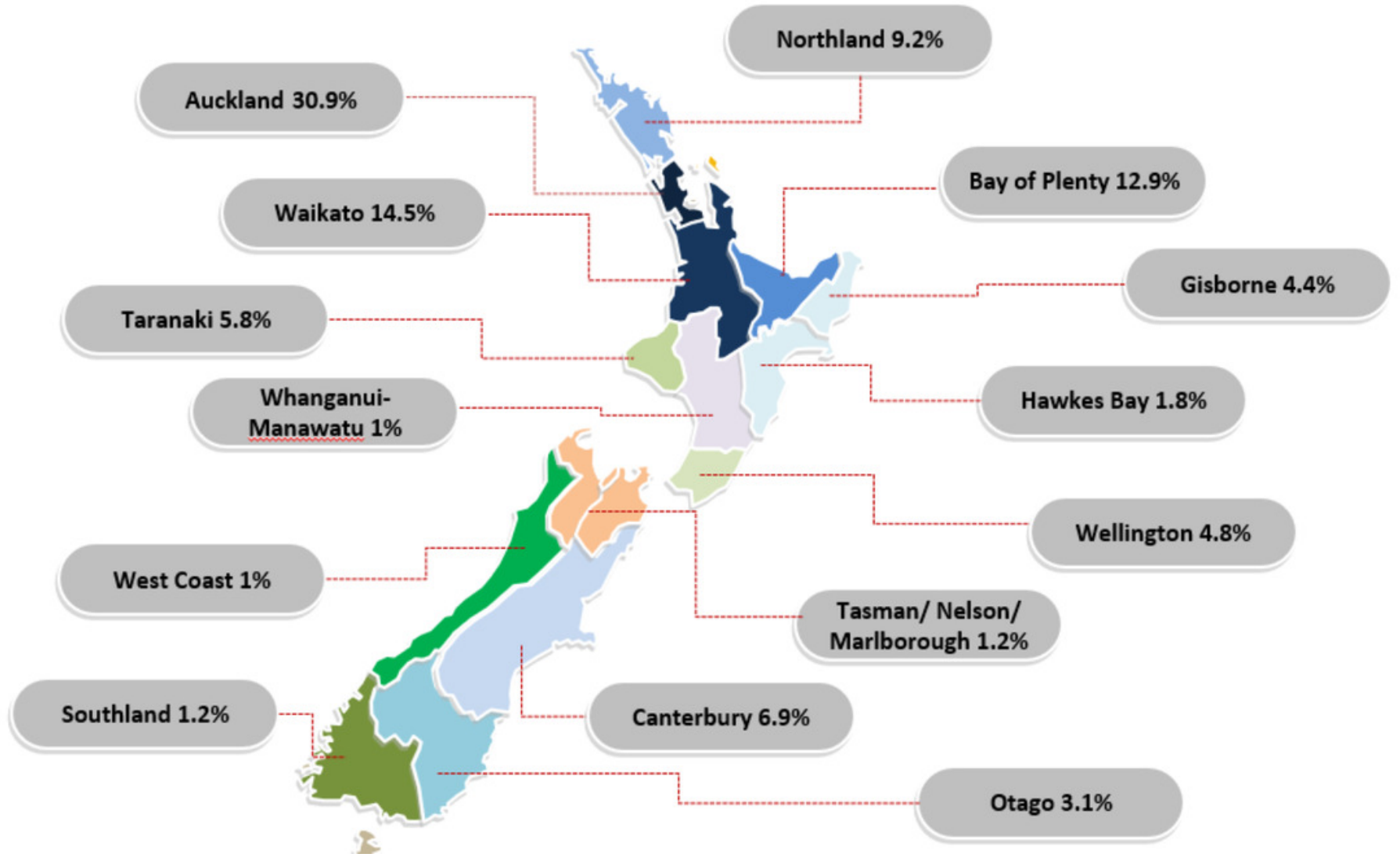


Figure 2

Comparison of incidence proportion between competitive and recreational surfers at 10 body locations.

*Indicates statistical significance $(P \leq 0.05)$

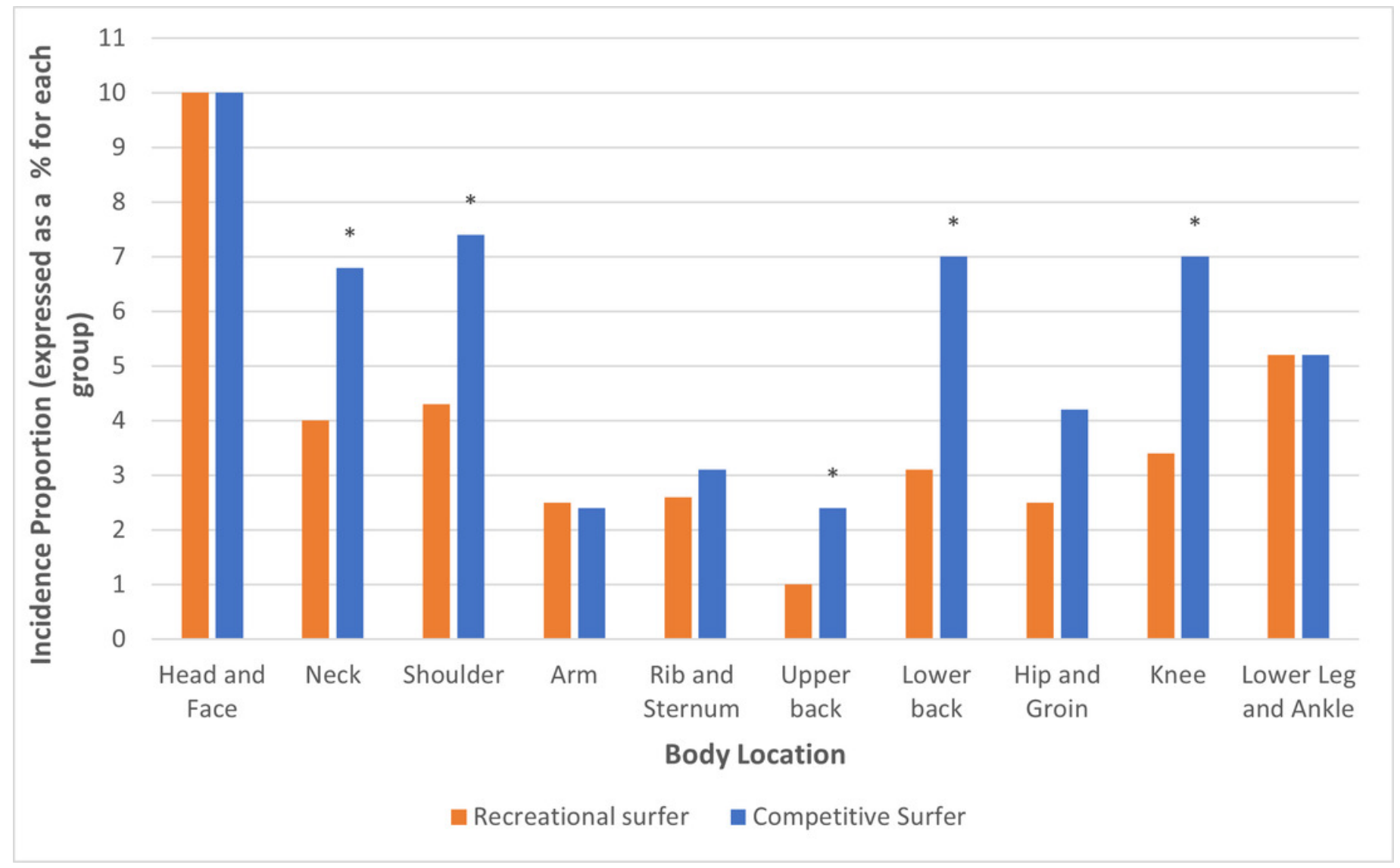


Figure 3

Comparison of acute and chronic injury duration major traumatic injuries by body location.

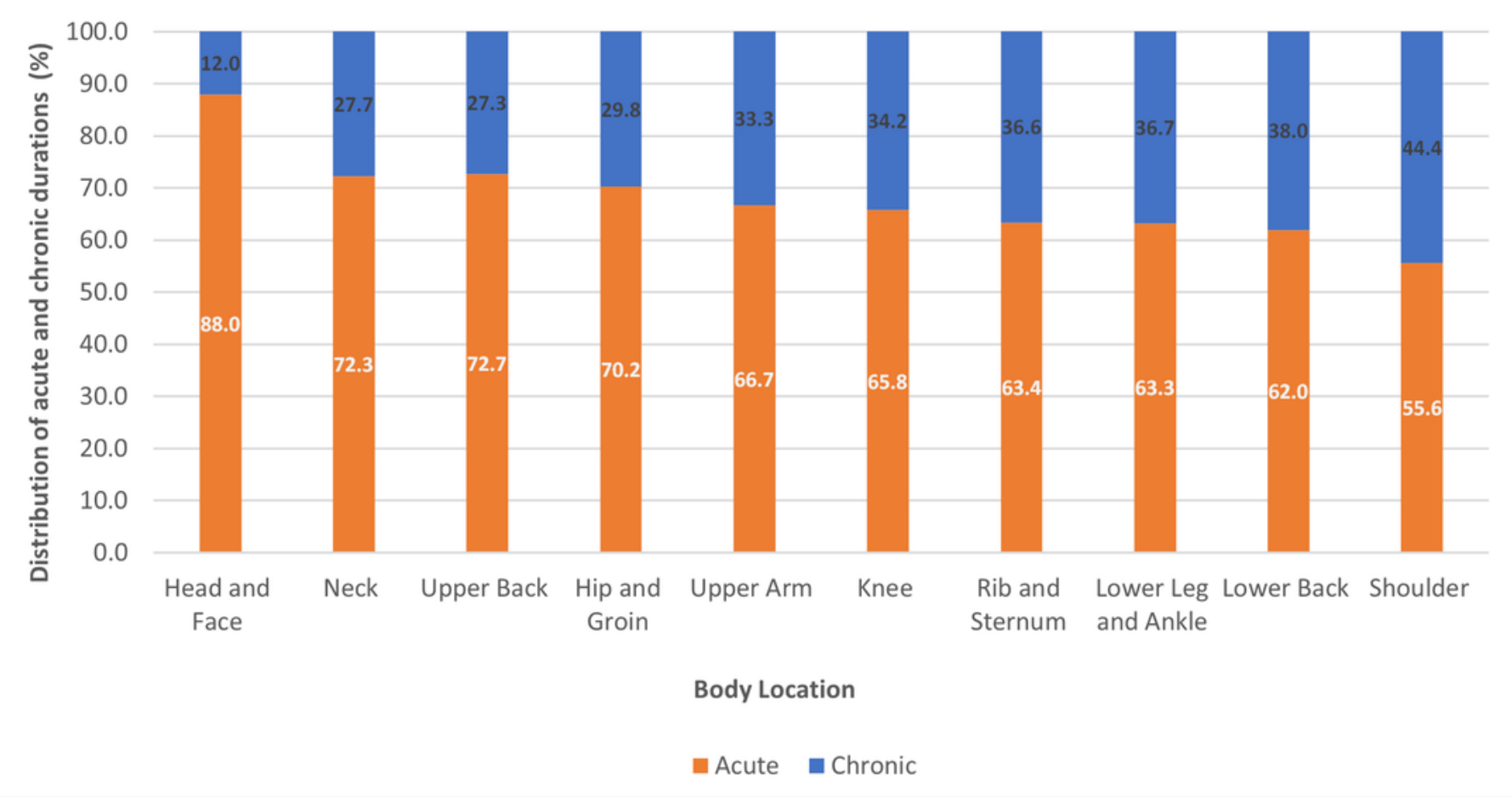

